\title{
End-of-Life Care Decision-Making in Stroke
}

\author{
Lucy Gao ${ }^{1}$, Charlie W. Zhao ${ }^{1}$ and David Y. Hwang ${ }^{2 *}$ \\ ${ }^{1}$ Yale School of Medicine, New Haven, CT, United States, ${ }^{2}$ Division of Neurocritical Care and Emergency Neurology, Yale \\ School of Medicine, New Haven, CT, United States
}

Stroke is one of the leading causes of death and long-term disability in the United States. Though advances in interventions have improved patient survival after stroke, prognostication of long-term functional outcomes remains challenging, thereby complicating discussions of treatment goals. Stroke patients who require intensive care unit care often do not have the capacity themselves to participate in decision making processes, a fact that further complicates potential end-of-life care discussions after the immediate post-stroke period. Establishing clear, consistent communication with surrogates through shared decision-making represents best practice, as these surrogates face decisions regarding artificial nutrition, tracheostomy, code status

Edited by:

Roland Faigle,

Johns Hopkins University,

United States

Reviewed by:

Claire Creutzfeldt,

University of Washington,

United States

Kate Brizzi,

Massachusetts General Hospital and

Harvard Medical School,

United States

Neha Kramer,

Rush University Medical Center

United States

*Correspondence:

David Y. Hwang

david.hwang@yale.edu

Specialty section:

This article was submitted to

Stroke,

a section of the journal

Frontiers in Neurology

Received: 30 April 2021

Accepted: 31 August 2021

Published: 28 September 2021

Citation:

Gao L, Zhao CW and Hwang DY

(2021) End-of-Life Care

Decision-Making in Stroke.

Front. Neurol. 12:702833.

doi: 10.3389/fneur.2021.702833 changes, and withdrawal or withholding of life-sustaining therapies. Throughout decision-making, clinicians must be aware of a myriad of factors affecting both provider recommendations and surrogate concerns, such as cognitive biases. While decision aids have the potential to better frame these conversations within intensive care units, aids specific to goals-of-care decisions for stroke patients are currently lacking. This mini review highlights the difficulties in decision-making for critically ill ischemic stroke and intracerebral hemorrhage patients, beginning with limitations in current validated clinical scales and clinician subjectivity in prognostication. We outline processes for identifying patient preferences when possible and make recommendations for collaborating closely with surrogate decision-makers on end-of-life care decisions.

Keywords: stroke, end-of-life, palliative care, goals-of-care, advance care planning, surrogate decision-maker, shared decision-making

\section{INTRODUCTION: EPIDEMIOLOGY OF LIFE-SUSTAINING THERAPY FOR SEVERE STROKE PATIENTS}

Stroke is a leading cause of death and long-term disability in the United States (US) $(1,2)$. The term "stroke" for this review focuses on two subtypes: acute ischemic stroke (AIS) and intracerebral hemorrhage (ICH). Clinicians are often confronted with issues related to end-of-life (EOL) care for stroke patients, such as code status, dysphagia care, and airway management (3). In order to tailor these decisions to patients' wishes, goals-of-care (GOC) discussions regarding acceptable quality of life (QoL) that require collaboration with surrogate decision-makers of incapacitated patients are needed.

Code status changes are among the earliest decisions that may occur during hospitalization for severe stroke. In practice, do-not-resuscitate (DNR) orders are often placed as early as within 24 hours of emergency department admission for both ICH (4) and AIS (5) patients. Approximately $13-26 \%$ of stroke patients receive DNR orders within 24 hours of admission $(4,5)$, with higher 
proportions of DNR status among those who later die of stroke $(6,7)$. There is concern that the act of making a patient DNR by itself affects clinicians' impressions of prognosis and independently increases the likelihood of mortality in AIS (5) and $\mathrm{ICH}(8,9)$. This possible "self-fulfilling prophecy" is a wellestablished concern in stroke care (10).

In the days to weeks after admission, issues of nutrition and airway management often come to the forefront of decisionmaking. Percutaneous endoscopic gastrostomy (PEG) placement is currently performed throughout the US in $8.8 \%$ of patients with AIS (11) and $10.4 \%$ for ICH (12), with variation amongst institutions $(11,12)$. Over half of PEG placements for AIS occur in the first week of admission (13). For stroke patients who have difficulty maintaining an open airway or who require prolonged mechanical ventilation, tracheostomy in the US is commonly performed 6-14 days after stroke onset $(14,15)$, with increasing numbers over the past two decades (14). Rates of life-sustaining interventions are higher in minority patients than white patients (16), including PEG $(17,18)$ and tracheostomy $(18)$.

In conjunction with these decisions, surrogates and clinical teams often decide to forgo life-sustaining measures and instead pursue comfort measures only (CMO). Withdrawal of lifesustaining therapy (WLST) is more common in neuro-intensive care units (Neuro-ICUs) than medical intensive care units (MICUs) (19), with up to $26 \%$ of all ICH patients in one singlecenter series undergoing WLST (20). Almost half of all stroke deaths occur inpatient (21), and hospitalized stroke patients have extensive palliative care needs $(22,23)$ that may not always be met. In one single-center US study from 2009-2015, about $4 \%$ of AIS patients were discharged to hospice (22).

In this brief review, we discuss the issues that arise when making EOL care decisions regarding stroke patients. We discuss prognostication tools, their limitations, methods to determine an incapacitated patient's wishes including advance care planning documentation (ACP) and best practices for shared decisionmaking with surrogates.

\section{PROGNOSTICATION: LIMITATIONS OF CLINICAL SCALES}

One factor in EOL decision-making involves prognostication of long-term outcome or natural disease history. Multiple clinical scales have been developed to predict mortality and functional outcome after stroke (24-26), several of which have been externally validated (Table $\mathbf{1}$ ).

Common predictor variables in AIS scales include age, stroke severity, pre-stroke functional status, comorbidities, and stroke subtype (24), with some scales utilizing imaging characteristics (36).

For ICH, many prognostication scales are based on variations of the "original" ICH score $(33,37-40)$, which was initially published with 30-day mortality data utilizing age, Glasgow Coma Scale at admission, ICH location, ICH volume, and presence of intraventricular hemorrhage (31).

Some published data suggest that scales largely outperform the "subjective" opinion of clinicians at predicting mortality and functional disability (41-43). However, these studies generally involved asking clinicians to prognosticate expected outcomes from hypothetical patient vignettes, which simplify and distill information that would otherwise be available in real-world clinical practice. In a comparison of the predictions of clinicians against common prognostication scales for 3-month functional status in real-world ICH patients, clinicians outperformed scales with regards to predictive accuracy (44).

This finding points towards the first of several limitations of prognostication scales-scales generate predictions using cohort data, yet prediction for individual patients may depend on variables not captured by scales. Furthermore, few models have been assessed for calibration (45) and robust external validation $(25,46)$, limiting their generalizability. Most scales were developed retrospectively, and data used to generate them include local practice patterns with regards to WLST, potentially incorporating the self-fulfilling prophesy. Finally, scales may not predict outcomes that are most important to patients and families, as the same functional outcome may lead to different perceptions of QoL for different patients. Clinicians have been shown to be poor at predicting a patient's future QoL, an inherently subjective quality, after stroke (47-49).

Despite these limitations, disclosing the results of a prognostication scale for a patient to a clinician impacts that clinician's clinical impression (50). Awareness of the limitations of scales can help ensure that the clinician utilizes these tools to complement clinical judgment rather than replace it. Recent studies suggest that making predictions based on clinical data from hospital day 5 rather than at admission may improve prognostication accuracy (51). Given the lack of objective tools for accurate prognostication and the potential for clinician bias to factor into decision-making, delaying prognostication may lead to improved prediction accuracy and clinical outcomes.

\section{GOALS-OF-CARE CONVERSATIONS: DETERMINING PATIENTS' WISHES}

Besides accurate neuro-prognostication, the ideal timing of GOC discussions regarding acceptable QoL for hospitalized stroke patients requires several considerations. GOC discussions, once initiated, are often iterative (1). Prognostic information should be tailored by amount and timing to the preferences of patients and families (52).

The aim of GOC discussions should be to ascertain the patient's wishes, or best estimates thereof, in order to provide goal-concordant care. As a means to this end, ACPs and surrogate decision-makers represent two sources of information for clinicians.

\section{Advance Care Planning Documentation}

Several types of ACPs (i.e. power of attorney, guardianship, living will, and Physician/Medical Orders for Life-Sustaining Treatment, or POLST/MOLST) exist, with variations in jurisdiction, applicability, and impact on decision-making (53). The only legally binding of these is POLST/MOLST, which serves 
TABLE 1 | Selected clinical scales developed for acute ischemic stroke and intracerebral hemorrhage.

\begin{tabular}{|c|c|c|c|}
\hline Scale & Original study & Predictors & Outcome variables \\
\hline \multicolumn{4}{|c|}{ Acute Ischemic Stroke } \\
\hline THRIVE & Flint et al., 2010 (27) & $\begin{array}{l}\text { NIHSS score, age, presence of hypertension, } \\
\text { diabetes, atrial fibrillation }\end{array}$ & $\begin{array}{l}\text { Mortality and mRS } 90 \text { days after stroke with } \\
\text { endovascular treatment }\end{array}$ \\
\hline iScore & Saposnik et al., 2011 (28) & $\begin{array}{l}\text { Age, sex, stroke severity, stroke subtype, comorbid } \\
\text { conditions, preadmission level of function, glucose } \\
\text { on admission }\end{array}$ & $\begin{array}{l}\text { Death at } 30 \text { days or } \mathrm{mRS}=3-5 \text { at discharge/Death at } \\
30 \text { days or institutionalization at discharge }\end{array}$ \\
\hline DRAGON & Strbian et al., 2012 (29) & $\begin{array}{l}\text { Early infarct signs on admission CT, pre-stroke mRS, } \\
\text { age, baseline glucose, onset to treatment time, } \\
\text { baseline NIHSS }\end{array}$ & mRS 3 months after stroke treated with IV tPA \\
\hline SOAR & Myint et al., 2014 (30) & $\begin{array}{l}\text { Age, gender, ischemic vs hemorrhagic stroke, } \\
\text { vascular territory, pre-stroke mRS }\end{array}$ & Inpatient and 7-day mortality \\
\hline \multicolumn{4}{|c|}{ Intracerebral hemorrhage } \\
\hline $\mathrm{ICH}$ score & Hemphill et al., 2001 (31) & GCS score, age, infratentorial origin, ICH volume, IVH & 30-day mortality \\
\hline $\begin{array}{l}\text { Modified ICH } \\
\text { score }\end{array}$ & $\begin{array}{l}\text { Cheung and Zou, } 2003 \\
\text { (32) }\end{array}$ & NIHSS, age, infratentorial origin, ICH volume, IVH & 30-day mortality or mRS score $\leq 2$ \\
\hline New ICH score & $\begin{array}{l}\text { Cheung and Zou, } 2003 \\
\text { (32) }\end{array}$ & $\begin{array}{l}\text { NIHSS, temperature, pulse pressure, IVH, } \\
\text { subarachnoid extension }\end{array}$ & 30-day mortality or mRS score $\leq 2$ \\
\hline $\mathrm{ICH}-\mathrm{GS}$ & $\begin{array}{l}\text { Ruiz-Sandoval et al., } 2007 \\
\text { (33) }\end{array}$ & GCS score, age, ICH location, ICH volume, IVH & 30-day mortality and GOS $\geq 4$ \\
\hline FUNC & Rost et al., 2008 (34) & $\begin{array}{l}\text { Age, GCS score, ICH location, ICH volume, pre-ICH } \\
\text { cognitive impairment }\end{array}$ & 90-day GOS $\geq 4$ \\
\hline $\max -\mathrm{ICH}$ & Sembill et al., 2017 (35) & ICH volume, age, NIHSS, IVH, oral anticoagulation & $\begin{array}{l}\text { 12-month mortality and mRS score in maximally treated } \\
\text { patients }\end{array}$ \\
\hline
\end{tabular}

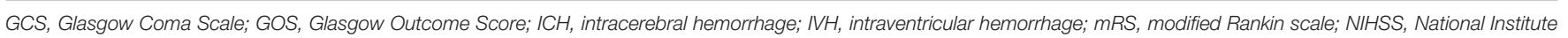
of Health Stroke Scale; tPA, tissue plasminogen activator.

as a standing medical order indicating a patient's wishes for treatment (54).

ACPs have variable effects on decision-making and come with several limitations. In a prospective study of hospitalized stroke patients, the presence of ACP documents and informal ACP conversations was associated with earlier transitions to $\mathrm{CMO}$ (55). However, other studies also specifically targeting stroke patients have suggested that the presence of ACPs does not affect clinicians' judgment for most decisions (56), implying other factors aside from ACPs play a greater role in decision-making. For instance, clinicians may endorse family members' choices for tube feeding despite contrary wishes expressed in living wills $(57,58)$.

Additionally, prevalence of ACPs in stroke patients is low (59); in studies of patients who died from stroke, fewer than half had completed ACPs $(60,61)$. Not all ACPs are readily available (61) or consistently documented (59). Though up to a quarter of strokes in the US are repeat strokes (62), ACP completion rates in stroke survivors are no different than that of the average older adult population (63). Some patients may experience financial and language barriers, as well as cultural factors, impacting ACP completion (64-66). This may also be due to the acute nature of stroke itself, making it difficult to have pre-emptive GOC conversations (67). Furthermore, ambiguous words, such as "incurable" (68) and states of "irreversible coma" are difficult to interpret in stroke (61). Most ACPs focus on specific procedures without clear-cut descriptions of scenarios pertinent to stroke (61), thus limiting their utility in determining patients' wider GOC.

\section{Identifying Surrogate Decision-Makers}

A second source of information for clinicians to ascertain a patient's GOC is the patient's surrogate. Patients with severe stroke often do not have capacity to participate in decisionmaking $(58,69)$. Though tools such as communication boards exist to aid select intubated patients in communicating their wishes (70), the vast majority of EOL cases in the Neuro-ICU require identifying surrogates (53).

In the absence of ACPs, clinicians typically follow a prioritized list of relatives according to state law (71). When no surrogate is available, protocols may involve committees or judiciary involvement (71). Great variation exists in the use of these resources by clinicians who make decisions to limit lifesustaining treatment in the ICU, suggesting further work is needed to develop procedures in these cases (72).

\section{SHARED DECISION-MAKING WITH SURROGATES: POTENTIAL PITFALLS Complexity of Decision-Making Factors}

After surrogates are identified, several factors play a role in shared EOL care decision-making. Generally, few surrogates of critically ill patients depend solely upon clinician prognoses when estimating their loved ones' prognoses themselves (73). Many endorse being influenced by a patient's physical appearance, their faith, and their understanding of the patient's will to live in addition to, and sometimes above, the clinician's prognostication (73). 
In qualitative studies, surrogates of stroke patients have endorsed reluctance in deciding to pursue CMO for loved ones (74). A recent study of nearly 800 US residents suggested that, when presented with a hypothetical scenario of a relative hospitalized with severe acute brain injury (requiring tracheostomy and PEG for survival), potential surrogates acknowledged a variety of competing concerns (75). While most surrogates prioritized respecting patients' perceived wishes and reducing suffering, surrogates may belong to different subgroups characterized by varying other top concerns: patient age, family agreement, prognostication, and cost of long-term care (75). Both non-white race and high religiosity may predict a surrogate choosing life-sustaining therapy over CMO (76). However, such a decision is still fraught with uncertainty; for example, respondents in the aforementioned study of US residents who were most concerned about cost of care were still more likely to choose tracheostomy and PEG placement over CMO compared with those less concerned (77). Clinicians must recognize that a variety of factors may influence surrogates in stroke-related GOC discussions.

\section{Cognitive and Emotional Biases}

Potential biases exist for both clinicians and surrogates collaborating to make shared EOL decisions. Towards recommending what (if any) additional treatments to pursue in stroke patients, a clinician may be influenced, for instance, by a desire to avoid personal or legal accusations by families of patients $(78)$ in addition to patient factors $(7,20)$. The clinician's prior experiences also affect these decisions; for instance, clinicians with experience in rehabilitation medicine tend to suggest continuation of life-sustaining therapy, perhaps due to a tendency to make positive prognoses (79). In these cases, clinicians may be biased towards what they would personally want in a similar situation rather than what the patient would want. In a study in which clinicians were presented vignettes of hypothetically critically-ill patients, clinician recommendations did not differ between groups who were provided the patient's values as expressed by family members vs. those who were not $(80)$.

Several common surrogate biases warrant discussion. First, in experimental settings, surrogates' interpretations of clinician prognostications were affected by numeracy skills (81) and were often overly optimistic (82). Second, surrogates may be subject to recall bias, remembering patients as more independent than they really were prior to illness (83).

Third, surrogates may be biased by their own perceptions of acceptable QoL in contrast to patients' own wishes. In a hypothetical scenario of stroke, surrogates' ratings of a patient's QoL were not reflective of the patient's own perceptions and desire for treatment (84). Levels of patient-proxy concordance varies by decision type, with surrogates accurately predicting patient preferences for reperfusion treatment $(85,86)$ but not clinical trial enrollment (86). When examining withdrawal of mechanical ventilation in stroke scenarios, patient-proxy agreement varied, with lowest levels of agreement when patients wanted everything done for treatment (87). Notably, despite these discrepancies, patients continue to exhibit high levels of trust in their surrogates (87-89).
Clinicians and surrogates alike may both be subject to the "disability paradox" bias-where people with serious disabilities may report greater QoL compared to healthy individuals envisaging similar circumstances $(83,90)$. However, clinicians must take into consideration long-term caregiver burden and take care not to offer an overly positive prognosis that is not warranted by objective clinical data.

\section{SHARED DECISION-MAKING WITH SURROGATES: IDEAL PROCESSES}

Essential elements of shared-decision making models are outlined by the Agency for Healthcare Research and Quality $(91,92)$. A recent survey of surrogates in the Neuro-ICU showed significant room for improvement in their inclusion in decisionmaking and clinician communication (93). For stroke patients specifically, caregivers may not comprehend the interventions that occurred (85) and feel overwhelming uncertainty $(94,95)$ throughout the decisional process. Families of stroke patients tend to have relatively low satisfaction with the attention given to communication and the needs of the family despite overall high satisfaction with palliative care administration (60). Almost a third of surrogates in the Neuro-ICU experience clinically significant grief and stress reactions (96). Surrogates may feel guilty about their decisions $(1,97)$ and often lack time to adapt during acute stroke when rapid treatment decisions are made (74).

\section{Best Practices for Communication}

Given these considerations, clinicians should approach the decision-making process collaboratively, negotiating the role of the clinician with surrogates (98) rather than taking a default paternalistic approach (99). Though few providers enquire about the surrogate's preferred role in decision-making (98), providers should ascertain a decision-maker's preferred level of control over EOL care decisions. Surrogates may want to make the final decision or consent to clinicians making decisions for the patient (100). Clear communication on the roles of the clinician and surrogate is key as discordancy between family members' preferred and actual decision-making roles is associated with increased depressive and post-traumatic stress disorder symptoms (101).

Our recommendations for family meetings are summarized in Table 2. Key participants to consider include interpreters (108), social workers $(1,104)$, spiritual care $(1,104,109)$, speech therapists $(110)$, and case managers $(1,104)$. Neuro-ICU nurseled family meetings can lead to greater feelings of control by families and higher satisfaction with care (111).

Clinicians should ensure consistent information from different providers $(104,105,112)$, use an "ask-tell-ask" approach (104) and give concrete descriptions of deficits (1). Using consistent terminology avoids confusion regarding seemingly interchangeable terms such as "brain bleed", "stroke", and "brain hemorrhage" (105). When prognosticating, acknowledging uncertainties is important, in addition to preparing families for worst-case scenarios while using "I wish" statements to preserve hope (113). Families of stroke patients are often aware 
TABLE 2 | Recommendations for shared decision-making with surrogate decision-makers after acute stroke.

\begin{tabular}{|c|c|}
\hline $\begin{array}{l}\text { Setting the Stage for } \\
\text { Goals-of-care }\end{array}$ & $\begin{array}{l}\text { - Ensure relevant participants are involved in family meetings (i.e. patient, family, other services) (102) } \\
\text { - Ask the surrogate decision-maker their preferences in terms of their role and that of the clinician in the shared decision-making } \\
\text { process (98) } \\
\text { - Utilize the ask-tell-ask approach by getting permission to present information, communicating information clearly, and checking for } \\
\text { understanding (103) }\end{array}$ \\
\hline $\begin{array}{l}\text { Communicating Prognostic } \\
\text { Uncertainty }\end{array}$ & $\begin{array}{l}\text { - Acknowledge uncertainty and explain why uncertainty exists (95) } \\
\text { - Communicate that prognosis can be altered by treatment decisions (1) } \\
\text { - Describe possible best and worst-case scenarios of survival and future quality of life (102) }\end{array}$ \\
\hline Eliciting Patient Preferences & $\begin{array}{l}\text { - With open-ended questions, ask what the patient valued in life (102) (i.e. "Tell me more about what [patient] liked to do before they } \\
\text { got sick") (103) } \\
\text { - Review advance care planning documents or the patient's verbally expressed wishes }(1,102)\end{array}$ \\
\hline Address Cognitive Biases & $\begin{array}{l}\text { - Consider discussing common recall and/or affective forecasting biases with decision-makers (102) } \\
\text { - Providing concrete descriptions of stroke survivors' functional outcomes after discharge may be helpful for de-biasing (83) }\end{array}$ \\
\hline Ongoing Communication & $\begin{array}{l}\text { - Demonstrate empathy in response to emotions (103) } \\
\text { - Continue to assess goals-of-care over time with regular meetings (1) } \\
\text { - Maintain consistency in communication across team members (104) and use consistent terminology to avoid confusion (105) }\end{array}$ \\
\hline Consider Time-Limited Trials & $\begin{array}{l}\text { - Can be used to reach consensus with families by giving patients who have a high likelihood of deteriorating a chance to respond to } \\
\text { treatments (106) } \\
\text { - Successful time-limited trials require defining the (1) intervention; (2) duration of intervention; (3) desired outcome; and (4) follow-up } \\
\text { plan that may include extending the trial and pursuing or forgoing further treatment (107) }\end{array}$ \\
\hline
\end{tabular}

of uncertainties in prognostication but require clarification as to why such uncertainty exists (95). Given concerns of numeracy skills (81), multiple portrayals of data should be offered if quantitative estimates of prognosis are offered; risks may be perceived as higher when presented as frequencies (e.g., 1 in 10) rather than equivalent percentages (e.g., 10\%) (114). Alternatively, some specialists recommend focusing on functional outcomes - with less emphasis on numerical estimates - using visual aids that illustrate the best, worst, and most likely scenarios (115). Time-limited trials can assess progress over time $(106,113)$ and help families come to terms with a patient's poor prognosis or manage uncertainty (Table 2).

How best to discuss prognostication and GOC after stroke remains a subject of ongoing discussion $(92,102)$. Decision aids, evidence-based interventions that outline the benefits/harms of decisions and their concordance with personal values (116), have been tested to assist in shared decision-making in ICUs $(92,117)$. A recent clinical trial using web-based decision aids for prolonged mechanical ventilation reduced surrogates' levels of decisional conflict, but did not improve prognostic concordance between clinicians and surrogates (118). Neuro-ICU-specific decision aids are currently few in number but are in development (92, 119-122). Future efforts could aim to identify different subgroups of surrogates in developing aids tailored to their priorities to facilitate shared decision-making after stroke (92).

\section{Expert Consultations}

Traditional palliative care needs are present in over half of Neuro-ICU patients $(123,124)$ and consults to palliative care services are used infrequently $(52,125)$. Even in those who die of stroke, palliative care involvement varies greatly from $26-90 \%$ $(52,126-128)$. Stroke may not trigger palliative care requests from family as other diagnoses, such as cancer, might (95). Despite recognizing the importance of palliative care in stroke, clinicians may feel uncertain about when to begin addressing palliative care needs (129). As such, palliative care specialists are often only brought in during the last days of life for symptomatic management of pain, dyspnea, and mood $(128,130,131)$.

It is recognized that having enough consultants to handle all palliative care needs in the Neuro-ICU may not be practical or appropriate in many situations. Palliative care consultations should not be initiated as a replacement for GOC conversations with the primary team (132). Neuro-ICU clinicians should be trained in and provide primary palliative care, including eliciting GOC and providing palliative treatments at EOL (113). However, expert palliative care consultants can help with symptom management, complicated conflict resolution, and eliciting further patient values/needs (133). Current palliative Neuro-ICU screening tools (123) and new models of palliative care delivery $(102,134-137)$ are being explored to assist clinicians with thresholds for consulting expert palliative care.

Conflicts may occur surrounding decisions of artificial nutrition/hydration $(60,74,112,138)$, resuscitation (112), and care transitions (112), particularly when impressions of prognosis are different between surrogates and clinicians despite multiple attempts at family conferences $(52,138,139)$. Though protocols differ, ethics consultations can help resolve conflicts between decision-makers and providers (140). Should providers believe that inappropriate treatment has been requested, a series of steps are recommended for conflict resolution by the American Thoracic Society $(141,142)$.

\section{CONCLUSION}

In this brief review, we discussed factors to consider when engaging in EOL decision-making, including prognostication, determining patient wishes, and interacting with surrogates with the goal of shared decision-making. 
It is important to note that even after decisions to WLST, families require ongoing support (95). Expectations must be discussed after WLST, which does not always mean imminent death $(1,143)$, as families often expect death early on and are distressed by prolonged dying processes (138).

\section{REFERENCES}

1. Frontera JA, Curtis JR, Nelson JE, Campbell M, Gabriel M, Mosenthal AC, et al. Integrating Palliative Care Into the Care of Neurocritically Ill Patients: A Report From the Improving Palliative Care in the ICU Project Advisory Board and the Center to Advance Palliative Care. Crit Care Med. (2015) 43:1964-77. doi: 10.1097/CCM.0000000000001131

2. Centers for Disease Control Prevention. Prevention prevalence of strokeunited states, 2006-2010. MMWR. (2012) 61:379-82.

3. Doubal F, Cowey E, Bailey F, Murray SA, Borthwick S, Somerville $\mathrm{M}$, et al. The key challenges of discussing end-of-life stroke care with patients and families: a mixed-methods electronic survey of hospital and community healthcare professionals. J R Coll Physicians Edinb. (2018) 48:217-24. doi: 10.4997/JRCPE.2018.305

4. Silvennoinen K, Meretoja A, Strbian D, Putaala J, Kaste M, Tatlisumak T. Donot-resuscitate (DNR) orders in patients with intracerebral hemorrhage. Int J Stroke. (2014) 9:53-8. doi: 10.1111/ijs.12161

5. Kelly AG, Zahuranec DB, Holloway RG, Morgenstern LB, Burke JF. Variation in do-not-resuscitate orders for patients with ischemic stroke: implications for national hospital comparisons. Stroke. (2014) 45:8227. doi: 10.1161/STROKEAHA.113.004573

6. Wang V, Hsieh CC, Huang YL, Chen CP, Hsieh YT, Chao TH. Different utilization of intensive care services (ICSs) for patients dying of hemorrhagic and ischemic stroke, a hospital-based survey. Medicine (Baltimore). (2018) 97:e0017. doi: 10.1097/MD.0000000000010017

7. Alonso A, Ebert AD, Dörr D, Buchheidt D, Hennerici MG, Szabo K. End-oflife decisions in acute stroke patients: an observational cohort study. BMC Palliat Care. (2016) 15:38. doi: 10.1186/s12904-016-0113-8

8. Creutzfeldt CJ, Becker KJ, Weinstein JR, Khot SP, McPharlin TO, Ton TG, et al. Do-not-attempt-resuscitation orders and prognostic models for intraparenchymal hemorrhage. Crit Care Med. (2011) 39:15862. doi: 10.1097/CCM.0b013e3181fb7b49

9. Zahuranec DB, Morgenstern LB, Sánchez BN, Resnicow K, White DB, Hemphill JC. Do-not-resuscitate orders and predictive models after intracerebral hemorrhage. Neurology. (2010) 75:626-33. doi: 10.1212/WNL.0b013e3181ed9cc9

10. Wartenberg KE, Hwang DY, Haeusler KG, Muehlschlegel S, Sakowitz OW, Madzar D, et al. Gap analysis regarding prognostication in neurocritical care: a joint statement from the german neurocritical care society and the neurocritical care society. Neurocrit Care. (2019) 31:23144. doi: 10.1007/s12028-019-00769-6

11. George BP, Kelly AG, Schneider EB, Holloway RG. Current practices in feeding tube placement for US acute ischemic stroke inpatients. Neurology. (2014) 83:874-82. doi: 10.1212/WNL.0000000000000764

12. Hwang DY, George BP, Kelly AG, Schneider EB, Sheth KN, Holloway RG. Variability in gastrostomy tube placement for intracerebral hemorrhage patients at US hospitals. J Stroke Cerebrovasc Dis. (2018) 27:97887. doi: 10.1016/j.jstrokecerebrovasdis.2017.11.001

13. George BP, Kelly AG, Albert GP, Hwang DY, Holloway RG. Timing of percutaneous endoscopic gastrostomy for acute ischemic stroke: an observational study from the US nationwide inpatient sample. Stroke. (2017) 48:420-7. doi: 10.1161/STROKEAHA.116.015119

14. Chatterjee A, Chen M, Gialdini G, Reznik ME, Murthy S, Kamel $\mathrm{H}$, et al. Trends in tracheostomy after stroke: analysis of the 1994 to 2013 national inpatient sample. The Neurohospitalist. (2018) 8:1716. doi: 10.1177/1941874418764815

15. Zhao CW, Hwang DY, Zhao CW, Gao L, George BP, Holloway RG, et al. US practitioner attitudes toward tracheostomy timing, benefits, risks, and techniques for severe stroke patients: a national survey and

\section{AUTHOR CONTRIBUTIONS}

LG, CZ, and DH all discussed the content of this manuscript in its planning stages. LG and CZ drafted this article, with subsequent revisions from DH. All authors contributed to the article and approved the submitted version.

national inpatient sample analysis. Neurocrit Care. (2020) 34:669-73. doi: 10.1007/s12028-020-01127-7

16. Xian Y, Holloway RG, Noyes K, Shah MN, Friedman B. Racial differences in mortality among patients with acute ischemic stroke: an observational study. Ann Intern Med. (2011) 154:152-9. doi: 10.7326/0003-4819-154-3-201102010-00004

17. Faigle R, Carrese JA, Cooper LA, Urrutia VC, Gottesman RF. Minority race and male sex as risk factors for non-beneficial gastrostomy tube placements after stroke. PLoS ONE. (2018) 13:e0191293. doi: 10.1371/journal.pone.0191293

18. Jones RC, Creutzfeldt CJ, Cox CE, Haines KL, Hough CL, Vavilala MS, et al. Racial and ethnic differences in health care utilization following severe acute brain injury in the United States. J Intensive Care Med. (2020). doi: 10.1177/0885066620945911. [Epub ahead of print].

19. Creutzfeldt CJ, Wunsch H, Curtis JR, Hua M. Prevalence and outcomes of patients meeting palliative care consultation triggers in neurological intensive care units. Neurocrit Care. (2015) 23:14-21. doi: 10.1007/s12028-015-0143-8

20. Reznik ME, Moody S, Murray K, Costa S, Grory BM, Madsen $\mathrm{TE}$, et al. The impact of delirium on withdrawal of life-sustaining treatment after intracerebral hemorrhage. Neurology. (2020) 95:e2727e35. doi: 10.1212/WNL.0000000000010738

21. Centers for Disease Control Prevention. Prevention place of death after stroke-United States, 1999-2002. MMWR Morbidity and Mortal Weekly Rep. (2006) 55:529-32.

22. Chauhan N, Ali SF, Hannawi Y, Hinduja A. Utilization of hospice care in patients with acute ischemic stroke. Am J Hosp Palliat Care. (2019) 36:28-32. doi: 10.1177/1049909118796796

23. Holloway RG, Ladwig S, Robb J, Kelly A, Nielsen E, Quill TE. Palliative care consultations in hospitalized stroke patients. J Palliat Med. (2010) 13:407-12. doi: 10.1089/jpm.2009.0278

24. Drozdowska BA, Singh S, Quinn TJ. Thinking about the future: a review of prognostic scales used in acute stroke. Front Neurol. (2019) 10:274. doi: 10.3389/fneur.2019.00274

25. Fahey M, Crayton E, Wolfe C, Douiri A. Clinical prediction models for mortality and functional outcome following ischemic stroke: a systematic review and meta-analysis. PLoS ONE. (2018) 13:e0185402. doi: 10.1371/journal.pone.0185402

26. Quinn TJ, Singh S, Lees KR, Bath PM, Myint PK, Collaborators V. Validating and comparing stroke prognosis scales. Neurology. (2017) 89:9971002. doi: 10.1212/WNL.0000000000004332

27. Flint AC, Cullen S, Faigeles B, Rao V. Predicting long-term outcome after endovascular stroke treatment: the totaled health risks in vascular events score. Am J Neuroradiol. (2010) 31:1192-6. doi: 10.3174/ajnr.A2050

28. Saposnik G, Kapral MK, Liu Y, Hall R, O’Donnell M, Raptis $\mathrm{S}$, et al. IScore: a risk score to predict death early after hospitalization for an acute ischemic stroke. Circulation. (2011) 123:739-49. doi: 10.1161/CIRCULATIONAHA.110.983353

29. Strbian D, Meretoja A, Ahlhelm F, Pitkäniemi J, Lyrer P, Kaste $\mathrm{M}$, et al. Predicting outcome of IV thrombolysis-treated ischemic stroke patients: The DRAGON score. Neurology. (2012) 78:427-32. doi: 10.1212/WNL.0b013e318245d2a9

30. Myint PK, Clark AB, Kwok CS, Davis J, Durairaj R, Dixit AK, et al. The SOAR (Stroke subtype, Oxford Community Stroke Project classification, Age, prestroke modified Rankin) score strongly predicts early outcomes in acute stroke. Int J Stroke. (2014) 9:278-83. doi: 10.1111/ijs.12088

31. Hemphill JC, 3rd. Bonovich DC, Besmertis L, Manley GT, Johnston SC. The ICH score: a simple, reliable grading scale for intracerebral hemorrhage. Stroke. (2001) 32:891-7. doi: 10.1161/01.STR.32.4.891 
32. Cheung RTF, Zou L-Y. Use of the original, modified, or new intracerebral hemorrhage score to predict mortality and morbidity after intracerebral hemorrhage. Stroke. (2003) 34:1717-22. doi: 10.1161/01.STR.0000078657.22835.B9

33. Ruiz-Sandoval JL, Chiquete E, Romero-Vargas S, PadillaMartínez JJ, González-Cornejo S. Grading scale for prediction of outcome in primary intracerebral hemorrhages. Stroke. (2007) 38:1641-4. doi: 10.1161/STROKEAHA.106.478222

34. Rost NS, Smith EE, Chang Y, Snider RW, Chanderraj R, Schwab $\mathrm{K}$, et al. Prediction of functional outcome in patients with primary intracerebral hemorrhage: the FUNC score. Stroke. (2008) 39:2304-9. doi: 10.1161/STROKEAHA.107.512202

35. Sembill JA, Gerner ST, Volbers B, Bobinger T, Lücking H, Kloska SP, et al. Severity assessment in maximally treated $\mathrm{ICH}$ patients: the max-ICH score. Neurology. (2017) 89:423-31. doi: 10.1212/WNL.0000000000004174

36. Soliman F, Gupta A, Delgado D, Kamel H, Pandya A. The role of imaging in clinical stroke scales that predict functional outcome: a systematic review. Neurohospitalist. (2017) 7:169-78. doi: 10.1177/1941874417708128

37. Chu SY, Hwang DY. Predicting outcome for intracerebral hemorrhage patients: current tools and their limitations. Semin Neurol. (2016) 36:25460. doi: 10.1055/s-0036-1581992

38. Bruce SS, Appelboom G, Piazza M, Hwang BY, Kellner C, Carpenter AM, et al. A comparative evaluation of existing grading scales in intracerebral hemorrhage. Neurocrit Care. (2011) 15:498-505. doi: 10.1007/s12028-011-9518-7

39. Satopaa J, Mustanoja S, Meretoja A, Putaala J, Kaste M, Niemela M, et al. Comparison of all 19 published prognostic scores for intracerebral hemorrhage. J Neurol Sci. (2017) 379:103-8. doi: 10.1016/j.jns.2017.05.034

40. Schmidt FA, Liotta EM, Prabhakaran S, Naidech AM, Maas MB. Assessment and comparison of the max-ICH score and ICH score by external validation. Neurology. (2018) 91:e939-e46. doi: 10.1212/WNL.0000000000006117

41. Persaud N, Thorpe KE, Raptis SR, Saposnik G, Stroke Outcomes Research Working G. Why clinicians prognosticate stroke patients poorly: results from the clinician judgment versus risk score to predict stroke outcomes randomized study. J Stroke Cerebrovasc Dis. (2016) 25:134954. doi: 10.1016/j.jstrokecerebrovasdis.2016.01.024

42. Saposnik G, Cote R, Mamdani M, Raptis S, Thorpe KE, Fang J, et al. JURaSSiC: accuracy of clinician vs risk score prediction of ischemic stroke outcomes. Neurology. (2013) 81:448-55. doi: 10.1212/WNL.0b013e31829d874e

43. Ntaios G, Gioulekas F, Papavasileiou V, Strbian D, Michel P, ASTRAL. DRAGON and SEDAN scores predict stroke outcome more accurately than physicians. Eur J Neurol. (2016) 23:1651-7. doi: 10.1111/ene.13100

44. Hwang DY, Dell CA, Sparks MJ, Watson TD, Langefeld CD, Comeau ME, et al. Clinician judgment vs formal scales for predicting intracerebral hemorrhage outcomes. Neurology. (2016) 86:126-33. doi: 10.1212/WNL.0000000000002266

45. Van Calster B, McLernon DJ, van Smeden M, Wynants L, Steyerberg EW. Topic Group 'Evaluating diagnostic T calibration: the Achilles heel of predictive analytics. BMC Med. (2019) 17:230. doi: 10.1186/s12916-019-1466-7

46. Jampathong N, Laopaiboon M, Rattanakanokchai S, Pattanittum P. Prognostic models for complete recovery in ischemic stroke: a systematic review and meta-analysis. BMC Neurol. (2018) 18:26. doi: 10.1186/s12883-018-1032-5

47. Finley Caulfield A, Gabler L, Lansberg MG, Eyngorn I, Mlynash M, Buckwalter MS, et al. Outcome prediction in mechanically ventilated neurologic patients by junior neurointensivists. Neurology. (2010) 74:1096101. doi: 10.1212/WNL.0b013e3181d8197f

48. Geurts M, de Kort FAS, de Kort PLM, van Tuijl JH, Kappelle LJ, van der Worp HB. Predictive accuracy of physicians' estimates of outcome after severe stroke. PLoS ONE. (2017) 12:e0184894. doi: 10.1371/journal.pone.0184894

49. Detsky ME, Kohn R, Delman AM, Buehler AE, Kent SA, Ciuffetelli IV, et al. Patients' perceptions and ICU clinicians predictions of quality of life following critical illness. J Crit Care. (2018) 48:3526. doi: 10.1016/j.jcrc.2018.09.034

50. Zahuranec DB, Fagerlin A, Sanchez BN, Roney ME, Thompson $\mathrm{BB}$, Fuhrel-Forbis A, et al. Variability in physician prognosis and recommendations after intracerebral hemorrhage. Neurology. (2016) 86:1864-71. doi: 10.1212/WNL.0000000000002676

51. Maas MB, Francis BA, Sangha RS, Lizza BD, Liotta EM, Naidech AM. Refining prognosis for intracerebral hemorrhage by early reassessment. Cerebrovasc Dis. (2017) 43:110-6. doi: 10.1159/000452679

52. Molidor S, Overbaugh KJ, James D, White CL. Palliative care and stroke: an integrative review of the literature. J Hosp Palliat Nurs. (2018) 20:35867. doi: 10.1097/NJH.0000000000000450

53. Cai X, Robinson J, Muehlschlegel S, White DB, Holloway RG, Sheth $\mathrm{KN}$, et al. Patient preferences and surrogate decision making in neuroscience intensive care units. Neurocrit Care. (2015) 23:131-41. doi: 10.1007/s12028-015-0149-2

54. POLST programs in your state. Available online at: https://polst.org/ programs-in-your-state/. (accessed December 19, 2020)

55. Lank RJ, Shafie-Khorassani F, Zhang X, Ortiz C, Kim S, Case E, et al. Advance care planning and transitions to comfort measures after stroke. J Palliat Med. (2021) 24:1191-6. doi: 10.1089/jpm.2020.0587

56. Qureshi AI, Chaudhry SA, Connelly B, Abott E, Janjua T, Kim SH, et al. Impact of advanced healthcare directives on treatment decisions by physicians in patients with acute stroke. Crit Care Med. (2013) 41:146875. doi: 10.1097/CCM.0b013e31827cab82

57. Ely JW, Jr., Peters PG, Zweig S, Elder N, Schneider FD. The physician's decision to use tube feedings: the role of the family, the living will, and the Cruzan decision. J Am Geriatr Soc. (1992) 40:471-5. doi: 10.1111/j.1532-5415.1992.tb02013.x

58. Seeber AA, Hijdra A, Vermeulen M, Willems DL. Discussions about treatment restrictions in chronic neurologic diseases: a structured review. Neurology. (2012) 78:590-7. doi: 10.1212/WNL.0b013e318247cc56

59. Johnson PD, Ulrich A, Siv J, Taylor B, Tirschwell D, Creutzfeldt CJ. Planning after stroke survival: advance care planning in the stroke clinic. J Am Heart Assoc. (2019) 8:e011317. doi: 10.1161/JAHA.118.011317

60. Blacquiere D, Bhimji K, Meggison H, Sinclair J, Sharma M. Satisfaction with palliative care after stroke: a prospective cohort study. Stroke. (2013) 44:2617-9. doi: 10.1161/STROKEAHA.113.001992

61. Alonso A, Dörr D, Szabo K. Critical appraisal of advance directives given by patients with fatal acute stroke: an observational cohort study. BMC Med Ethics. (2017) 18:7. doi: 10.1186/s12910-016-0166-5

62. Benjamin EJ, Blaha MJ, Chiuve SE, Cushman M, Das SR, Deo $\mathrm{R}$, et al. Heart disease and stroke statistics-2017 update: a report from the American Heart Association. Circulation. (2017) 135:e146603. doi: 10.1161/CIR.0000000000000491

63. Skolarus LE, Lin CC, Springer MV, Burke JF. Advance care planning among stroke survivors in the United States. Neurology. (2020) 95:8746. doi: 10.1212/WNL.0000000000010832

64. Nedjat-Haiem FR, Carrion IV, Gonzalez K, Quintana A, Ell K, O'Connell M, et al. Implementing an advance care planning intervention in community settings with older latinos: a feasibility study. J Palliat Med. (2017) 20:98493. doi: 10.1089/jpm.2016.0504

65. Carrion IV, Nedjat-Haiem FR, Martinez-Tyson D, Castañeda $H$. Advance care planning among Colombian, Mexican, and Puerto Rican women with a cancer diagnosis. Support Care Cancer. (2013) 21:1233-9. doi: 10.1007/s00520-012-1652-z

66. Carrion IV. Communicating terminal diagnoses to hispanic patients. Palliat Support Care. (2010) 8:117. doi: 10.1017/S147895150999085X

67. Creutzfeldt CJ, Longstreth W, Holloway RG. Predicting decline and survival in severe acute brain injury: the fourth trajectory. BMJ. (2015) 351:h3904. doi: 10.1136/bmj.h3904

68. Leder N, Schwarzkopf D, Reinhart K, Witte OW, Pfeifer R, Hartog CS. The validity of advance directives in acute situations. Dtsch Arztebl Int. (2015) 112:723-9. doi: 10.3238/arztebl.2015.0723

69. de Kort FAS, Geurts M, de Kort PLM, van Tuijl JH, van Thiel G, Kappelle LJ, et al. Advance directives, proxy opinions, and treatment restrictions in patients with severe stroke. BMC Palliat Care. (2017) 16:52. doi: 10.1186/s12904-017-0234-8

70. Patak L, Gawlinski A, Fung NI, Doering L, Berg J, Henneman EA. Communication boards in critical care: patients' views. Appl Nurs Res. (2006) 19:182-90. doi: 10.1016/j.apnr.2005.09.006

71. Mahanes D. Ethical concerns caring for the stroke patient. Crit Care Nurs Clin North Am. (2020) 32:121-33. doi: 10.1016/j.cnc.2019.11.001 
72. White DB, Curtis JR, Lo B, Luce JM. Decisions to limit life-sustaining treatment for critically ill patients who lack both decision-making capacity and surrogate decision-makers. Crit Care Med. (2006) 34:2053-9. doi: 10.1097/01.CCM.0000227654.38708.C1

73. Boyd EA, Lo B, Evans LR, Malvar G, Apatira L, Luce JM, et al. "It's not just what the doctor tells me:" factors that influence surrogate decision-makers' perceptions of prognosis. Crit Care Med. (2010) 38:1270-5. doi: 10.1097/CCM.0b013e3181d8a217

74. de Boer ME, Depla M, Wojtkowiak J, Visser MC, Widdershoven GA, Francke AL, et al. Life-and-death decision-making in the acute phase after a severe stroke: interviews with relatives. Palliat Med. (2015) 29:451-7. doi: 10.1177/0269216314563427

75. Hwang DY, Knies AK, Mampre D, Kolenikov S, Schalk M, Hammer $\mathrm{H}$, et al. Concerns of surrogate decision makers for patients with acute brain injury: a US population survey. Neurology. (2020) 94:e2054e68. doi: 10.1212/WNL.0000000000009406

76. Knies AK, Zhang Q, Juthani P, Tu S, Pach J, Martinez A, et al. Psychological attachment orientations of surrogate decision-makers and goals-of-care decisions for brain injury patients in ICUs. Crit Care Explor. (2020) 2:e0151. doi: 10.1097/CCE.0000000000000151

77. Garg A, Soto AL, Knies AK, Kolenikov S, Schalk M, Hammer H, et al. Predictors of surrogate decision makers selecting life-sustaining therapy for severe acute brain injury patients: an analysis of US population survey data. Neurocrit Care. (2021) 1-12. doi: 10.1007/s12028-021-01200-9

78. Turnbull AE, Sahetya SK, Biddison ELD, Hartog CS, Rubenfeld GD, Benoit DD, et al. Competing and conflicting interests in the care of critically ill patients. Intensive Care Med. (2018) 44:1628-37. doi: 10.1007/s00134-018-5326-2

79. Rogge A, Witt VD, Valdueza JM, Borzikowsky C, Buyx A. Experience in rehabilitation medicine affects prognosis and end-of-life decision-making of neurologists: a case-based survey. Neurocrit Care. (2019) 31:12534. doi: 10.1007/s12028-018-0661-2

80. Turnbull AE, Krall JR, Ruhl AP, Curtis JR, Halpern SD, Lau BM, et al. A scenario-based, randomized trial of patient values and functional prognosis on intensivist intent to discuss withdrawing life support. Crit Care Med. (2014) 42:1455. doi: 10.1097/CCM.0000000000000227

81. Leiter N, Motta M, Reed RM, Adeyeye T, Wiegand DL, Shah NG, et al. Numeracy and interpretation of prognostic estimates in intracerebral hemorrhage among surrogate decision makers in the neurologic ICU. Crit Care Med. (2018) 46:264-71. doi: 10.1097/CCM.0000000000002887

82. Zier LS, Sottile PD, Hong SY, Weissfield LA, White DB. Surrogate decision makers' interpretation of prognostic information: a mixed-methods study. Ann Intern Med. (2012) 156:3606. doi: 10.7326/0003-4819-156-5-201203060-00008

83. Creutzfeldt CJ, Holloway RG. Treatment decisions after severe stroke: uncertainty and biases. Stroke. (2012) 43:34058. doi: 10.1161/STROKEAHA.112.673376

84. Bravo G, Sene M, Arcand M. Surrogate inaccuracy in predicting older adults' desire for life-sustaining interventions in the event of decisional incapacity: is it due in part to erroneous quality-of-life assessments? Int Psychogeriatr. (2017) 29:1061-8. doi: 10.1017/S1041610217000254

85. Pressler H, Reich A, Schulz JB, Nikoubashman O, Willmes K, Habib P, et al. Modern interdisciplinary and interhospital acute stroke therapy-what patients think about it and what they really understand. J Stroke Cerebrovasc Dis. (2018) 27:2669-76. doi: 10.1016/j.jstrokecerebrovasdis.2018.05.029

86. Bryant J, Skolarus LE, Smith B, Adelman EE, Meurer WJ. The accuracy of surrogate decision makers: informed consent in hypothetical acute stroke scenarios. BMC Emerg Med. (2013) 13:18. doi: 10.1186/1471-227X-13-18

87. Hinderer KA, Friedmann E, Fins JJ. Withdrawal of life-sustaining treatment: patient and proxy agreement: a secondary analysis of "contracts, covenants, and advance care planning". Dimens Crit Care Nurs. (2015) 34:919. doi: 10.1097/DCC.0000000000000097

88. McMahan RD, Knight SJ, Fried TR, Sudore RL. Advance care planning beyond advance directives: perspectives from patients and surrogates. J Pain Symptom Manage. (2013) 46:355-65. doi: 10.1016/j.jpainsymman.2012.09.006

89. Barrio-Cantalejo IM, Molina-Ruiz A, Simón-Lorda P, Cámara-Medina C, Toral Lopez I. del Mar Rodriguez del Aguila M, et al. Advance directives and proxies' predictions about patients' treatment preferences. Nursing Ethics. (2009) 16:93-109. doi: 10.1177/0969733008097995
90. Albrecht GL, Devlieger PJ. The disability paradox: high quality of life against all odds. Social science \& medicine. (1999) 48:977-88. doi: 10.1016/S0277-9536(98)00411-0

91. Quality AfHRa. The SHARE approach: 5 essential steps to shared decisionmaking (2014). Available online at: https://www.ahrq.gov/health-literacy/ professional-training/shared-decision/index.html. (accessed December 12, 2020)

92. Khan MW, Muehlschlegel S. Shared decision making in neurocritical care. Neurosurg Clin N Am. (2018) 29:315-21. doi: 10.1016/j.nec.2017.11.009

93. Hwang DY, Yagoda D, Perrey HM, Tehan TM, Guanci M, Ananian L, et al. Assessment of satisfaction with care among family members of survivors in a neuroscience intensive care unit. J Neurosci Nurs. (2014) 46:10616. doi: 10.1097/JNN.0000000000000038

94. Connolly T, Coats H, DeSanto K, Jones J. The experience of uncertainty for patients, families and healthcare providers in post-stroke palliative and end-of-life care: a qualitative meta-synthesis. Age Ageing. (2020) 50:534-45. doi: 10.1093/ageing/afaa229

95. Payne S, Burton C, Addington-Hall J, Jones A. End-of-life issues in acute stroke care: a qualitative study of the experiences and preferences of patients and families. Palliat Med. (2010) 24:146-53. doi: 10.1177/0269216309350252

96. Trevick SA, Lord AS. Post-traumatic stress disorder and complicated grief are common in caregivers of neuro-ICU patients. Neurocrit Care. (2017) 26:436-43. doi: 10.1007/s12028-016-0372-5

97. Wendler D, Rid A. Systematic review: the effect on surrogates of making treatment decisions for others. Ann Intern Med. (2011) 154:33646. doi: 10.7326/0003-4819-154-5-201103010-00008

98. White DB, Malvar G, Karr J, Lo B, Curtis JR. Expanding the paradigm of the physician's role in surrogate decision-making: an empirically derived framework. Crit Care Med. (2010) 38:743-50. doi: 10.1097/CCM.0b013e3181c58842

99. Bailoor K, Valley T, Perumalswami C, Shuman AG, DeVries R, Zahuranec DB. How acceptable is paternalism? A survey-based study of clinician and nonclinician opinions on paternalistic decision making. AJOB Empir Bioeth. (2018) 9:91-8. doi: 10.1080/23294515.2018.1462273

100. Johnson SK, Bautista CA, Hong SY, Weissfeld L, White DB. An empirical study of surrogates' preferred level of control over value-laden life support decisions in intensive care units. Am J Respir Crit Care Med. (2011) 183:91521. doi: 10.1164/rccm.201008-1214OC

101. Gries CJ, Engelberg RA, Kross EK, Zatzick D, Nielsen EL, Downey L, et al. Predictors of symptoms of posttraumatic stress and depression in family members after patient death in the ICU. Chest. (2010) 137:2807. doi: 10.1378/chest.09-1291

102. Knies AK, Hwang DY. Palliative care practice in neurocritical care. Semin Neurol. (2016) 36:631-41. doi: 10.1055/s-0036-1592358

103. Milic MM, Puntillo K, Turner K, Joseph D, Peters N, Ryan R, et al. Communicating with patients' families and physicians about prognosis and goals of care. Am J Crit Care. (2015) 24:e56-64. doi: 10.4037/ajcc2015855

104. Hudoba C, Hwang DY. Goals of Care and Difficult Conversations. Neurocritical Care for the Advanced Practice Clinician, Springer. (2018). p. 343-61. doi: 10.1007/978-3-319-48669-7_19

105. Zahuranec DB, Anspach RR, Roney ME, Fuhrel-Forbis A, Connochie DM, Chen EP, et al. Surrogate decision makers' perspectives on family members' prognosis after intracerebral hemorrhage. J Palliat Med. (2018) 21:95662. doi: 10.1089/jpm.2017.0604

106. Quill TE, Holloway R. Time-limited trials near the end of life. JAMA. (2011) 306:1483-4. doi: 10.1001/jama.2011.1413

107. Holloway RG, Benesch CG, Burgin WS, Zentner JB. Prognosis and decision making in severe stroke. JAMA. (2005) 294:72533. doi: 10.1001/jama.294.6.725

108. Silva MD, Genoff M, Zaballa A, Jewell S, Stabler S, Gany FM, et al. Interpreting at the end of life: a systematic review of the impact of interpreters on the delivery of palliative care services to cancer patients with limited english proficiency. J Pain Symptom Manage. (2016) 51:56980. doi: 10.1016/j.jpainsymman.2015.10.011

109. Gordon BS, Keogh M, Davidson Z, Griffiths S, Sharma V, Marin D, et al. Addressing spirituality during critical illness: a review of current literature. J Crit Care. (2018) 45:76-81. doi: 10.1016/j.jcrc.2018.01.015

110. Winstein CJ, Stein J, Arena R, Bates B, Cherney LR, Cramer $\mathrm{SC}$, et al. Guidelines for adult stroke rehabilitation and recovery: a guideline for healthcare professionals from the American 
Heart Association/American Stroke Association. Stroke. (2016) 47:e98-e169. doi: 10.1161/STR.0000000000000098

111. Wu H, Ren D, Zinsmeister GR, Zewe GE, Tuite PK. Implementation of a nurse-led family meeting in a neuroscience intensive care unit. Dimens Crit Care Nurs. (2016) 35:268-76. doi: 10.1097/DCC.0000000000000199

112. Eriksson H, Andersson G, Olsson L, Milberg A, Friedrichsen M. Ethical dilemmas around the dying patient with stroke: a qualitative interview study with team members on stroke units in Sweden. J Neurosci Nurs. (2014) 46:162-70. doi: 10.1097/JNN.0000000000000049

113. Holloway RG, Arnold RM, Creutzfeldt CJ, Lewis EF, Lutz BJ, McCann RM, et al. Palliative and end-of-life care in stroke: a statement for healthcare professionals from the American Heart Association/American Stroke Association. Stroke. (2014) 45:1887-916. doi: 10.1161/STR.0000000000000015

114. Chapman AR, Litton E, Chamberlain J, Ho KM. The effect of prognostic data presentation format on perceived risk among surrogate decision makers of critically ill patients: a randomized comparative trial. J Crit Care. (2015) 30:231-5. doi: 10.1016/j.jcrc.2014.11.005

115. Kruser JM, Nabozny MJ, Steffens NM, Brasel KJ, Campbell TC, Gaines ME, et al. "Best Case/Worst Case": qualitative evaluation of a novel communication tool for difficult in-the-moment surgical decisions. $J \mathrm{Am}$ Geriatr Soc. (2015) 63:1805-11. doi: 10.1111/jgs.13615

116. Stacey D, Légaré F, Lewis K, Barry MJ, Bennett CL, Eden KB, et al. Decision aids for people facing health treatment or screening decisions. Cochrane database of systematic reviews. (2017) 4:Cd001431. doi: 10.1002/14651858.CD001431.pub5

117. Cox CE, Lewis CL, Hanson LC, Hough CL, Kahn JM, White DB, et al. Development and pilot testing of a decision aid for surrogates of patients with prolonged mechanical ventilation. Crit Care Med. (2012) 40:232734. doi: 10.1097/CCM.0b013e3182536a63

118. Cox CE, White DB, Hough CL, Jones DM, Kahn JM, Olsen MK, et al. Effects of a personalized web-based decision aid for surrogate decision makers of patients with prolonged mechanical ventilation: a randomized clinical trial. Ann Intern Med. (2019) 170:285-97. doi: 10.7326/M18-2335

119. Muehlschlegel S, Shutter L, Col N, Goldberg R. Decision aids and shared decision-making in neurocritical care: an unmet need in our NeuroICUs. Neurocrit Care. (2015) 23:127-30. doi: 10.1007/s12028-014-0097-2

120. Chen EP, Arslanian-Engoren C, Newhouse W, Egleston D, Sahgal S, Yande A, et al. Development and usability testing of Understanding Stroke, a tailored life-sustaining treatment decision support tool for stroke surrogate decision makers. BMC Palliat Care. (2020) 19:110. doi: 10.1186/s12904-020-00617-x

121. Goostrey KJ, Lee C, Jones K, Quinn T, Moskowitz J, Pach JJ, et al. Adapting a traumatic brain injury goals-of-care decision aid for critically Ill patients to intracerebral hemorrhage and hemispheric acute ischemic stroke. Crit Care Explor. (2021) 3:e0357. doi: 10.1097/CCE.0000000000000357

122. Muehlschlegel S, Hwang DY, Flahive J, Quinn T, Lee C, Moskowitz $\mathrm{J}$, et al. Goals-of-care decision aid for critically ill patients with TBI: development and feasibility testing. Neurology. (2020) 95:e179e93. doi: 10.1212/WNL.0000000000009770

123. Creutzfeldt CJ, Engelberg RA, Healey L, Cheever CS, Becker KJ, Holloway RG, et al. Palliative care needs in the Neuro-ICU. Crit Care Med. (2015) 43:1677-84. doi: 10.1097/CCM.0000000000001018

124. Trevick S, Kim M, Naidech A. Communication, leadership, and decision-making in the Neuro-ICU. Curr Neurol Neurosci Rep. (2016) 16:99. doi: 10.1007/s11910-016-0699-5

125. Bar B, Creutzfeldt CJ, Rubin MA. Palliative care in the neuroICU: perceptions, practice patterns, and preferences of neurointensivists. Neurocrit Care. (2020) 32:302-5. doi: 10.1007/s12028-019-00838-w

126. Quadri SZ, Huynh T, Cappelen-Smith C, Wijesuriya N, Mamun A, Beran $\mathrm{RG}$, et al. Reflection on stroke deaths and end-of-life stroke care. Intern Med J. (2018) 48:330-4. doi: 10.1111/imj.13619

127. Blacquiere DP, Gubitz GJ, Dupere D, McLeod D, Phillips S. Evaluating an organized palliative care approach in patients with severe stroke. Can J Neurol Sci. (2009) 36:731-4. doi: 10.1017/S0317167100008349

128. Mazzocato C, Michel-Nemitz J, Anwar D, Michel P. The last days of dying stroke patients referred to a palliative care consult team in an acute hospital. Eur J Neurol. (2010) 17:73-7. doi: 10.1111/j.1468-1331.2009.02744.x

129. Gardiner C, Harrison M, Ryan T, Jones A. Provision of palliative and end-of-life care in stroke units: a qualitative study. Palliat Med. (2013) 27:855-60. doi: 10.1177/0269216313483846
130. Steigleder T, Kollmar R, Ostgathe C. Palliative Care for Stroke Patients and Their Families: Barriers for Implementation. Front Neurol. (2019) 10:164. doi: 10.3389/fneur.2019.00164

131. Ackroyd J, Nair A. 114 Palliative care and the acute stroke ward: new beginnings? British Medical Journal Publishing Group (2018). doi: 10.1136/bmjspcare-2018-ASPabstracts.141

132. Carson SS, Cox CE, Wallenstein S, Hanson LC, Danis M, Tulsky JA, et al. Effect of palliative care-led meetings for families of patients with chronic critical illness: a randomized clinical trial. Jama. (2016) 316:5162. doi: 10.1001/jama.2016.8474

133. Tran LN, Back AL, Creutzfeldt CJ. Palliative care consultations in the neuro-ICU: a qualitative study. Neurocrit Care. (2016) 25:26672. doi: 10.1007/s12028-016-0283-5

134. Nelson JE, Bassett R, Boss RD, Brasel KJ, Campbell ML, Cortez $\mathrm{TB}$, et al. Models for structuring a clinical initiative to enhance palliative care in the intensive care unit: a report from the IPAL-ICU Project (Improving Palliative Care in the ICU). Crit Care Med. (2010) 38:1765. doi: 10.1097/CCM.0b013e3181e8ad23

135. Aslakson RA, Curtis JR, Nelson JE. The changing role of palliative care in the ICU. Crit Care Med. (2014) 42:2418. doi: 10.1097/CCM.0000000000000573

136. Akgün KM, Kapo JM, Siegel MD, editors. Critical care at the end of life. Seminars in respiratory and critical care medicine. Thieme Medical Publishers. (2015)

137. Creutzfeldt CJ, Holloway RG, Curtis JR. Palliative care: a core competency for stroke neurologists. Stroke. (2015) 46:27149. doi: 10.1161/STROKEAHA.115.008224

138. Cowey E, Smith LN, Stott DJ, McAlpine CH, Mead GE, Barber $\mathrm{M}$, et al. Impact of a clinical pathway on end-of-life care following stroke: a mixed methods study. Palliat Med. (2015) 29:249-59. doi: 10.1177/0269216314551378

139. Rogers A, Addington-Hall J. Care of the dying stroke patient in the acute setting. J Res Nurs. (2005) 10:153-67. doi: 10.1177/174498710501000208

140. Neal JB, Pearlman RA, White DB, Tolchin B, Sheth KN, Bernat JL, et al. Policies for mandatory ethics consultations at US academic teaching hospitals: a multisite survey study. Crit Care Med. (2020) 48:84753. doi: $10.1097 / C C M .0000000000004343$

141. Bosslet GT, Pope TM, Rubenfeld GD, Lo B, Truog RD, Rushton $\mathrm{CH}$, et al. An Official ATS/AACN/ACCP/ESICM/SCCM policy statement: responding to requests for potentially inappropriate treatments in intensive care units. Am J Respir Crit Care Med. (2015) 191:131830. doi: 10.1164/rccm.201505-0924ST

142. Hwang DY. Discussing Life-sustaining Therapy With Surrogate Decision Makers. Continuum (Minneap Minn). (2017) 23:2548. doi: 10.1212/CON.0000000000000417

143. Qureshi AI, Adil MM, Suri MF. Rate of utilization and determinants of withdrawal of care in acute ischemic stroke treated with thrombolytics in USA. Med Care. (2013) 51:1094-100. doi: 10.1097/MLR.0b013e3182 a95db4

Conflict of Interest: DH has received philanthropic funds from the Apple Pickers Foundation (Westerly, RI) for pilot testing of decision aids for families of patients with severe acute brain injury.

The remaining authors declare that the research was conducted in the absence of any commercial or financial relationships that could be construed as a potential conflict of interest.

Publisher's Note: All claims expressed in this article are solely those of the authors and do not necessarily represent those of their affiliated organizations, or those of the publisher, the editors and the reviewers. Any product that may be evaluated in this article, or claim that may be made by its manufacturer, is not guaranteed or endorsed by the publisher.

Copyright $\odot 2021$ Gao, Zhao and Hwang. This is an open-access article distributed under the terms of the Creative Commons Attribution License (CC BY). The use, distribution or reproduction in other forums is permitted, provided the original author(s) and the copyright owner(s) are credited and that the original publication in this journal is cited, in accordance with accepted academic practice. No use, distribution or reproduction is permitted which does not comply with these terms. 